Macedonian Pharmaceutical Bulletin, 66 (Suppl 1) 223 - 224 (2020)

Online ISSN 1857 - 8969

UDC: 615:364-787.9(497.7)

DOI: 10.33320/maced.pharm.bull.2020.66.03.111

Short communication

\title{
Pharmaceutical care - a patient right to health care service in R.N. Macedonia
}

\author{
Iskra Jordanovska*, Katerina Anchevska-Netkovska, \\ Aleksandra Kapedanovska Nestorovska, Aleksandra Grozdanova
}

Faculty of Pharmacy, Ss. Cyril and Methodius University, Mother Theresa 47, 1000 Skopje, N. Macedonia

\section{Introduction}

The healthcare system is an exceptionally important segment of the social country which needs to provide constant quality and continuous health protection as stated in the Health Care Law of Republic of North Macedonia "Every citizen has the right to obtain the health protection by respecting the highest possible standard of human rights and values, that means having the right to physical and psychological integrity and security of his/her personality, as well as to his/her moral, cultural, religious and philosophical beliefs" (Law on Health Protection, 2012).

Reaching the highest attainable standard of health, it's not only a primarily patient right but a fundamental right of human beings and medicines are considered as priorities of attaining this right (WHO). In this context, not only providing medicines, but also their rational use is indispensable responsibility of the health care system. Despite the reorganization of health care and social services, the growing expectations of society demands for services that are more focused on the individual patient, a higher quality of health care within the community and a more effective patient participation in decisions. A multi-disciplinary approach is needed to develop, implement and evaluate the interventions to promote a more rational use of medicines.

\footnotetext{
*ijordanovska@yahoo.com
}

\section{Pharmaceutical care: framework for redefining the pharmaceutical practice}

Pharmaceutical care is a philosophy of practice in which the patient needs, not the drug, are the focal point of the pharmacist's actions-attitudes, behaviors, commitments, concerns, ethics, functions, knowledge, responsibilities and skills intended to provide rational pharmacotherapy that will improve treatment outcomes and thus patient health and quality of life. Pharmaceutical care as a patientcentered, outcome oriented practice, strives to provide safe, efficient, evidence-based and costeffective drug treatment individualized to patient needs according to the "5 Rights" concept - the right drug to the right patient, in the right dose and right route of administration, at the right time. Pharmaceutical Care recognizes the pharmacist as a health care provider who actively participates in the prevention of illness and the promotion of health of the patients, along with other responsible members of the health care team. Pharmaceutical Care practitioner cannot replace the physician, the dispensing pharmacist, nurse or any other health care provider and vice versa. Therefore, the hierarchy driven relationship has to be abandoned and all health care workers in the multidisciplinary team have to accept each other as a partners in achieving the best for the patient (Dalton and Byrne, 2017; EDQM, 2012). 


\section{Pharmaceutical care services: contributing to improved healthcare system}

Pharmaceutical care services, along with Public health interventions and effective medicines supply management, are key components of the rational use of drugs. Common types of irrational use include failure to prescribe, dispense, and use medicines as per guidelines, use too many medicines, inappropriate use of antibacterials, overuse where not required, underuse where required, inadequate use for chronic diseases, self-medication and use of expensive low-efficacy, low safety drugs. Published evidence shows that implementation of Pharmaceutical care services (eg. Medication Reconciliation, Adherence and Knowledge assessments, Medication Optimization, Patient Counseling) effectively prevents the irrational drug use resulting in decreased rate of morbidity, mortality, adverse drug reactions, antimicrobial resistance and financial loss (Dalton and Byrne, 2017).

\section{Pharmaceutical care - focus on patient rights to quality health care}

Pharmaceutical care ethics is the core principal in the set of pharmacist's actions that puts patients' rights first: the patient has to have all of the information about medicines he uses; the patient has to be actively involved in making health care decision and has to articulate the desired outcome. Thus, the impact of implementation this concept, directly corresponds on the rate of patient's rights accomplishment. At the same time, patients have responsibilities too, such as being reasonable and polite, using the medicines with awareness and communicate any problem that may arise with their medication during the therapy (Code of Ethics for Pharmacists in the Republic of North Macedonia; Law on Protection of Patients` Rights, 2008).

\section{Implementation and regulation of Pharmaceutical care services}

Regulation, as part of the public policies that guarantee health safety, is an important and essential element for the provision of quality services and products. It is defined as the capacity to generate new laws and regulations aimed at improving the health of the population. Actually, it represents the institutional capacity to develop the regulatory framework to protect public health. This function should be outlined in the national health care and pharmaceutical policies. The concept of pharmaceutical care has been well defined and broadly implemented in developed health care systems - hospitals and community pharmacy settings both. Conversely, its implementation in developing countries, as R.N. Macedonia is still theoretical and practically nonexistent with no regulation that allows the attainment of contracted pharmaceutical care services. The pharmacy is not considered as a location of "health care services" delivery, but only as a location of "retail and dispensing drugs service".

\section{Conclusion}

Traditional concept of health care in R.N. Macedonia has already reached its limit, being necessarily to transform it, in line with the time and needs of patients nowadays. The clinical, humanistic and economic benefit of implementation of Pharmaceutical care as a patient right to a quality health care service at all levels of the health care systems in the developed countries is evident. In our country, implementation of pharmaceutical care services faces significant barriers and many challenges. A change in orientation of the pharmaceutical services with a new pharmaceutical care functions and responsibilities requires a development of a totally new regulatory framework or a huge change in the existing ones.

\section{References}

Code of Ethics for Pharmacists in the Republic of Macedonia ("Official Gazette of the Republic of Macedonia" nos.33/2014).

Dalton, K., Byrne, S., 2017. Role of the pharmacist in reducing healthcare costs: current insights. Integr. Pharm. Res. Pract. 6, 37-46.

European Directorate for the Quality of Medicines \& HealthCare, EDQM, 2012. Pharmaceutical care; Policies and Practices for a Safer, More Responsible and Cost-effective Health System.

Law on Health Protection ("Official Gazette of the Republic of Macedonia" nos. 43/2012).

Law on Protection of Patients` Rights ("Official Gazette of the Republic of Macedonia") nos. 82/2008.

Maced. Pharm. Bull. 66 (Suppl 1) 223 - 224 (2020) 